\title{
Comprometimento e alinhamento da pós-graduação da PUC-Rio com o desenvolvimento sustentável
}

\section{Commitment and alignment of the post-graduation education of Catholic University of Rio de Janeiro with the sustainable development}

\section{El compromiso y la alineación del posgrado de la PUC- Rio con el desarrollo sostenible}

\begin{abstract}
Maurício Nogueira Frota, coordenador do Programa de PósGraduação em Metrologia da PUC-Rio. Endereço: Programa de Pós-Graduação em Metrologia (PósMQI/PUC-Rio) - Rua Marquês de São Vicente, 225 - Gávea. CEP: 22453-900 - Rio de Janeiro, RJ. Telefone: (21) 3527-1542/2053/ 9341-0659.E-mail:mfrota@ puc-rio.br.
\end{abstract}

Fabrício Casarejos Lopes Luiz, doutor em Física Experimental na área de Biofísica pela Pontifícia Universidade Católica do Rio de Janeiro (PUC-Rio) e pós-doutor em Metrologia na área de Qualidade, Inovação e Sustentabilidade (PósMQI/PUC-Rio). Endereço: Programa de Pós-Graduação em Metrologia (PósMQI/ PUC-Rio) - Rua Marquês de São Vicente, 225 - Gávea. CEP: 22453900 - Rio de Janeiro, RJ. Telefone: (21) 3527-1542/2053. E-mail: casarejos@esp.puc-rio.br.

\section{Resumo}

Em sintonia com a temática "a pós-graduação e o desenvolvimento sustentável" desta edição da Revista Brasileira de Pós-Graduação, o artigo reflete o comprometimento da Pontifícia Universidade Católica do Rio de Janeiro (PUC-Rio) com o desenvolvimento sustentável. Destaca ações já empreendidas em resposta a recomendações das conferências das Nações Unidas sobre o meio ambiente e o desenvolvimento sustentável (1972, 1980, 
1992 e 2012) e do Colóquio Global de Reitores de Universidades (N. York University, 1987), do qual participaram reitores das principais universidades do mundo. Cônscia de sua responsabilidade, a PUCRio pautou o seu compromisso na ética ambiental voltada para a transformação da cultura antropocêntrica com vistas à integralização do ser humano pela preservação da biodiversidade e do meio ambiente. No contexto de uma ação integrada da universidade, discute a consolidação do pilar sustentabilidade no seu Programa de PósGraduação em Metrologia para Qualidade e Inovação.

Palavras-chave: Desenvolvimento Sustentável. Sustentabilidade. PósGraduação. Metrologia. Qualidade. Inovação.

\section{Abstract}

In line with the theme "post-graduate education and sustainable development" of this issue of the Brazilian Journal of PostGraduate Education, the article indicates the commitment of the Catholic University of Rio de Janeiro (PUC-Rio) to sustainable development. It highlights actions already taken in response to recommendations of the United Nations Conferences on the environment and sustainable development (1972, 80, 92 e 2012) and of the "Global Colloquium of University Chancellors" (New York University, 1987), attended by rectors of leading universities in the world. Aware of its responsibility, PUC-Rio oriented its commitment to environmental ethics toward the transformation of anthropocentric culture in order to better integrate the human being into processes of biodiversity and environmental preservation. In the context of an integrated action of the university, the article discusses the consolidation of the pillar sustainability in its Postgraduate Programme in Metrology for Quality and Innovation.

Keywords: Sustainable Development. Sustainability. Postgraduate Education. Metrology. Quality. Innovation.

\section{Resumen}

En consonancia con el tema "el posgrado y el desarrollo sostenible” de esta edición de la Revista Brasileña de Posgrado, este 
artículo refleja el compromiso de la PUC-Rio con el desarrollo sostenible. Se destacan medidas adoptadas en respuesta a las recomendaciones de las conferencias de las Naciones Unidas sobre el medio ambiente y el desarrollo sostenible $(1972,1980,1992$ y 2012) y del Coloquio Mundial de Rectores de Universidades (N. York University 1987), al que asistieron rectores de las principales universidades del mundo. Consciente de su responsabilidad, la PUC-Rio orientó su compromiso con la ética ambiental hacia la transformación de la cultura antropocéntrica con el fin de integrar el ser humano a la preservación de la biodiversidad y del medio ambiente. En el contexto de una acción integrada de la universidad, se analiza la consolidación del pilar de la sostenibilidad en su Programa de Posgrado en Metrología para la Calidad y la Innovación.

Palabras clave: Desarrollo Sostenible. Sostenibilidad. Posgrado. Metrología. Calidad. Innovación.

\section{O vocábulo sustentabilidade e os riscos da sua plurivalência}

Do ponto de vista linguístico, o étimo sustentar, de que se origina o termo sustentabilidade, provém de sustentare (sustinere), verbo latino que designa ações verbais de conteúdo similar. Figurativamente, amplia sua significação para expressar ideias contíguas (defender; afirmar categoricamente; alimentar; fazer subsistir; amparar) e tantas mais. Não obstante o conceito ser antigo - segurar por baixo; suportar; escorar; ajudar; auxiliar; servir; impedir um desequilíbrio ou queda; servir de barreira (LELLO, 1926; BOFF, 2012) -, sustentabilidade é um conceito que ganhou o mundo nos últimos anos para designar o bom uso das riquezas naturais do planeta (UNCSD/RIO+20, 2012).

Como se nota, o significado de seus congêneres não difere tanto um do outro. Chama a atenção, no entanto, a sua aplicação atual e insistente em teses acadêmicas e outras publicações científicas das mais diversas áreas do conhecimento, na mídia em geral, nas políticas públicas do mundo inteiro, nos discursos político-ideológicos, em propagandas e marketing tão díspares quanto alimento e automóvel. Dessa sobre-exposição do termo, aleatória em muitos dos casos, 
emergiu um sentido inusitado: o de perigo iminente contra a vida humana e o universo natural. Qual o perigo? O de que o planeta não consiga mais, por exaustão e fadiga de suas forças naturais e impotência para neutralizar os escombros resultantes da intervenção do homem na natureza, sustentar a vida lato sensu na Terra. Fala-se, desse modo, de dois termos mútuo-dependentes: habitat natural e preservação da vida, ou seja, meio ambiente e condição de vida, cujo fôlego cresce na proporção que a informação sobre esse processo devastador avança e atinge praticamente todos os extratos sociais. O pensamento contemporâneo elegeu, então, o substantivo sustentabilidade para arrimo de teses relativas à necessidade de alinhar o processo desenvolvimentista à manutenção das condições de vida no planeta (UNCSD/RIO+20, 2012). Ou seja, o de preservar o equilíbrio viável entre a necessidade de desenvolvimento e a preservação dos recursos naturais que garantam a sobrevivência do binômio desenvolvimento e condição de ótima qualidade de vida.

Do ponto de vista meramente filosófico, sustentabilidade pode ser compreendida como o meio de possibilitar um projeto civilizatório humano cujo fim último seria o alcance universal do equilíbrio entre o desenvolvimento e a preservação das fontes de vida futura. E, do ponto de vista pragmático, como estratégia para a consecução desse meio. A designação indiscriminada, e por vezes oportunista, do termo sustentável e de seus cognatos para referência de políticas desenvolvimentistas tão diversas quanto as sociais, culturais, econômicas ou mesmo religiosas acabou gerando uma polissemia que impede sua inteligibilidade universal, bem como os limites claros de práticas "sustentáveis" igualmente universais.

Embora a introdução do conceito de sustentabilidade seja comumente atribuída à Comissão Mundial sobre o Meio Ambiente e Desenvolvimento (BRUNDTLAND, 1987), já em 1560, na Saxônia (Alemanha), fazia-se menção à nachhaltigkeit para referir-se ao que hoje se entende por sustentabilidade. Na realidade, um movimento originado na preocupação com o uso intensivo dos recursos madeireiros e escasseamento das riquezas da floresta levou a uma visão nova de redirecionamento da exploração sustentável da floresta para que fosse 
"capaz de se manter e regenerar suas riquezas" (CARLOWITZ, 2000, p. 105), "permitindo às futuras gerações dispor das mesmas vantagens que a atual" (GROBER, 2003, p. 167).

Não obstante as questões e contradições que o conceito sustentabilidade ainda suscita no âmbito da investigação científica, reconhece-se, entretanto, a contribuição do Relatório Bruntdland para o seu entendimento:

Desenvolvimento sustentável: aquele que atende às necessidades das gerações atuais sem comprometer a capacidade das gerações futuras de atender às suas necessidades e aspirações (BRUNTDLAND, 1987, p. 54).

No contexto desse relatório, a definição encerra, essencialmente, dois conceitos-chave: (i) os conceitos de necessidades, em particular, as necessidades essenciais da pobreza universal, que deveria merecer prioridade absoluta; e (ii) a ideia de limitações impostas pelo estado de tecnologia e organização social sobre a capacidade de o ambiente atender a necessidades presentes e futuras. Foi dessa iniciativa da ONU que se reconheceu ser de interesse comum de todas as nações o estabelecimento de políticas comuns de desenvolvimento sustentável e de os problemas ambientais serem de natureza global.

Tal conceituação parece ter-se popularizado e se tornado jargão corrente no discurso oficial da sociedade contemporânea. Percebe-se aí uma atitude de aproximação aos princípios e critérios delineados no Relatório Bruntdland por instituições governamentais e não governamentais, que passaram a anunciar publicamente a adoção do Triple Bottom Line para modelo padrão de desenvolvimento, cuja base assenta-se em três pilares: o do economicamente viável, o do socialmente justo e o do ambientalmente correto (ELKINGTON, 1990).

A leitura do modelo de desenvolvimento padrão, compreendido no chamado Triple Bottom Line constante do Relatório Bruntdland, leva aos seguintes questionamentos: em que medida consegue-se definir e determinar as necessidades das gerações atuais e, sobretudo, das futuras gerações? Qual o grau de confiabilidade desse processo de definição e determinação? Quais os processos envolvidos na 
capacidade física do planeta em suprir tais necessidades? Quais os limites da capacidade-suporte dos recursos e serviços ecossistêmicos? Quais as grandezas físicas envolvidas nos processos fundamentais que mantêm a homeostase climática? Como se comportam tais processos? Como estabelecer limites e trajetórias desejáveis para os padrões de uso, operação e consumo de recursos e serviços ecossistêmicos? Como quantificar e qualificar fisicamente a regeneração/recomposição e a biodiversidade? Quais os critérios utilizáveis para a seleção das métricas e dos indicadores necessários para a correta avaliação do desenvolvimento? Como orientar um processo de inovação em condicionamento estável da habitabilidade do planeta e da prosperidade do projeto civilizatório? Como determinar o real impacto antrópico sobre a interconectividade física, química e biológica de toda a vida e processos existentes no planeta? Como elaborar estratégias efetivas em níveis local e global capazes de conferir adaptação às mudanças climáticas? E, considerando as questões anteriores, como mensurar, quantificar e qualificar com confiabilidade no modelo Triple Bottom Line o viável do econômico, o justo do social e o correto do ambiental? (MEADOWS; RANDERS; MEADOWS, 2004; IPCC, 2007).

Tais questionamentos indicam uma necessidade: a de se construir uma amálgama de conhecimentos capaz de compreender o sentido intrinsecamente complexo da sustentabilidade da vida e da qualidade de vida no planeta. Nesse contexto, um desafio inédito e uma ampla responsabilidade se mostram por inteiro para as sociedades: 0 de buscar soluções que permitam a construção de um modelo confiável e, portanto, verificável de desenvolvimento em bases sustentáveis.

\section{0 papel das universidades com o desenvolvimento sustentável}

A universidade, classicamente entendida, define-se como centro de produção de conhecimento e saber. Produz conhecimento sem perder de vista o horizonte de sua aplicação direta na transformação do homem e da sociedade que, em verdade, são o seu fim e a razão mesma de sua existência. Nesse processo de transmissão do saber em que a interação social é condição essencial, a universidade educa 
no sentido original do termo. Ou seja: leva, conduz, orienta, nisso consistindo o peso real de sua responsabilidade quanto à formação do cabedal humano que dali evade para atuar e, em grande parte, liderar nas mais diversas frentes do tecido social, seja ele político, social ou religioso. Claro fica, no âmbito dessa compreensão, que o grau de interferência no desenvolvimento social remonta quase sempre ao embrião universitário, que inclui, incisivamente, no momento político atual, a questão da importância da sustentabilidade para a segurança das condições ótimas da vida presente e futura. Assim, se a razão do instituto universitário pode ser entendida no bojo da "assepsia" meramente científica, sua finalidade trai a singularidade desse caráter único por causa mesmo da sua finalidade - o homem e a vida - por onde permeia a noção de valor: o que vale e o que não vale; o que conta e o que desconta no âmbito da existência humana e de seu habitat. Essa noção de valor obriga, em última instância, à educação para uma ética solidária, bem como para o desenvolvimento de linguagens, símbolos, ferramentas científicas e tecnológicas adequadas a esse fim (LUKMAN; GLAVIC, 2007).

A promoção da importância da sustentabilidade na universidade pode e deve ser conseguida por meio da criação de programas acadêmicos de recorte "sustentável" determinado. Essencialmente, de parcerias e de redes cooperativas, de forma a consolidar uma cultura intra e extramuro universitário dessa disciplina voltada para o desenvolvimento sustentável, pois são as instituições universitárias que, pela sua vocação natural, promovem a sinergia ideal e espontânea entre docentes, discentes, funcionários e a sociedade, assim potencializando a elaboração de soluções inovadoras.

O reconhecimento mundial do papel das universidades na construção de saberes voltados ao desenvolvimento sustentável pode ser observado nos documentos oficiais dedicados a discutir a incorporação da sustentabilidade às instituições de ensino e pesquisa. Entre os quais, pode-se citar:

- A Declaração de Estocolmo (SOHN, 1973): primeira a explicitar a necessidade do ensino e da formação em educação ambiental;

- A Declaração de Tbilisi (THE TBILISI DECLARATION, 1977): veio reforçar a importância da educação ambiental na 
preservação e melhoria da biodiversidade e do meio ambiente;

- A Declaração de Talloires (THE TALLOIRES DECLARATION, 1990): enalteceu o papel de liderança da universidade na indução de uma consciência para o desenvolvimento ambientalmente sustentável; na criação de uma cultura institucional da sustentabilidade; na educação voltada para a cidadania ambientalmente responsável; na proposição de práticas de ecologia institucional; no engajamento das partes interessadas; e na colaboração construtiva destinada à expansão de abordagens interdisciplinares;

- A Declaração de Halifax (THE HALIFAX DECLARATION, 1991) e a Declaração de Kyoto (THE KYOTO DECLARATION, 1993): ambas propuseram um conjunto de ações para as universidades, tais como utilizar seus recursos intelectuais para incentivar a compreensão da sociedade acerca dos riscos dos impactos antrópicos e das alterações climáticas; enfatizar a responsabilidade da geração atual com a sustentabilidade e os danos pela inobservância à devida utilização dos recursos naturais e serviços ambientais; e ensinar e praticar princípios sustentáveis;

- As Declarações de Thessaloniki (THE THESSALONIKI DECLARATION, 1997) e de Swansea (THE SWANSEA DECLARATION, 1993): soaram o alerta de que a regressão da não sustentabilidade somente seria viável mediante a compugnação de todos os segmentos da sociedade contra as más práticas vigentes;

- A Carta de Copernicus (COPERNICUS GUIDELINES, 1993): compilou um conjunto de diretrizes estratégicas destinadas a facilitar a incorporação de temas sobre desenvolvimento sustentável e mudanças climáticas nas instituições de ensino superior europeias;

- A Declaração Mundial sobre o Ensino Superior para o Século XXI - visão e ação (WORLD, 1993): composta por 17 artigos, faz do ensino o pilar fundamental dos direitos humanos, da democracia, da paz mundial e da busca do desenvolvimento sustentável sua premissa maior; e 
- A Declaração de Luneburg (LUNEBURG DECLARATION, 2001): emanada da conferência sobre Higher Education for Sustainability: Towards the World Summit on Sustainable Development 2002, delineou um conjunto de critérios e princípios para a incorporação da sustentabilidade em instituições de ensino superior, precedendo os muitos outros documentos que a esse se seguiram.

Percebe-se que a extração de um denominador comum para a assimilação e adoção de medidas de proteção e desenvolvimento da sustentabilidade por parte de instituições tão distintas, embora complementares (e.g.: instituições de ensino, governos, associações e organizações sociais livres), teve importância fundamental na tomada definitiva de consciência desse problema que ameaça a vida qualificada lato sensu.

Dessa forma, e considerando as proposições e os resultados do UNED (United Nations Environment and Development) (capítulo 36 da AGENDA 21, 1995); do International Work Programme on Education, Public Awareness and Training for Sustainability, adotado pelas Nações Unidas (Commission on Sustainable Development, 1996); as conclusões da International Conference on Environment and Society (THESSALONIKI, 1997); as definições da World Conference on Higher Education (Paris, 1998); da World Conference on Science (Budapest, 1999); do World Education Forum (Education for All, Dakar, 2002); e reportando-se ainda aos avanços na formação de redes entre três associações acadêmicas que constituem a GHESP (Global Higher Education for Sustainability Partnership, que conta com o suporte inicial de mil faculdades e universidades comprometidas com a implementação de ações voltadas para o entendimento do desenvolvimento sustentável), foram sumarizadas as medidas concludentes de indiscutivel relevância:

- assegurar a atualização e revisão do conceito científico sustentabilidade;

- priorizar o tema desenvolvimento sustentável no processo de formação continuada dos professores;

- prover a atualização formal e continuada de professores, 
lideranças e do público em geral em desenvolvimento sustentável;

- incentivar instituições de ensino a incluir nas suas atividades o exercício reflexivo sobre valores e normas afetas a desenvolvimento sustentável;

- elevar o grau de alerta e intensificar a compreensão da importância e relevância de uma avaliação tecnológica e dos riscos correlatos à não sustentabilidade;

- incentivar a criatividade para o desenvolvimento e a implementação de projetos direcionados à sustentabilidade em institutos de ensino superior e outros;

- atentar para a dimensão internacional do problema e incentivar a troca internacional em conhecimento ambiental;

- aumentar o foco no potencial desenvolvimentista e intensificar a formação de redes (enredamento) entre as instituições educacionais;

- fortalecer a integração entre treinamento e pesquisa, bem como a interação com os financiadores ao longo do processo de desenvolvimento; e

- pressionar governos de forma a assegurar que a educação em geral e a educação superior, em particular, estejam contempladas no programa de trabalho internacional (World Summit on Sustainable Development).

Por fim, cabe salientar a Declaração de Ubuntu (2002), que propôs uma aliança global entre todas as instituições em prol do ensino, da pesquisa e da cultura do desenvolvimento sustentável.

As discussões estabelecidas por essas declarações atestam o reconhecimento mundial do papel a ser desempenhado pelas universidades na construção de um modelo de desenvolvimento em bases sustentáveis, muito embora o desafio devencera própria definição do conceito de sustentabilidade paire real e claro. Ou seja, a dificuldade de abranger concomitantemente diferentes culturas e grupos, cuja apreensão de termo condiciona-se a interferentes específicos, como cultura, visão própria do mundo, propósitos e interesses específicos. Portanto, materializar e operacionalizar os conceitos da chamada 
ciência da sustentabilidade é um desafio complexo a exigir a difícil (mas não impossível) sinergia entre os saberes, os cidadãos, as instituições e as sociedades.

\section{O papel da PUC-Rio na construção da sustentabilidade}

A Pontifícia Universidade Católica do Rio de Janeiro (PUCRio), reconhecidamente um campo de produção do saber, manteve, paralelamenteà sua missão imediata degerar edistribuir conhecimento, o alinhamento às teses humanistas de valorização do homem como ser comprometido com a espiritualidade imanente à edificação da vida lato sensu. Nesse sentido, sua conformidade com a ênfase atual no conceito sustentabilidade como via de reconstrução de um mundo futuro mais humano e, portanto, mais solidário sempre existiu na base fundamental de seu projeto educacional. Projeto diferenciado em que uma espécie de civismo cognoscitivo prevaleceu e prevalece sobre o pragmatismo puro das ciências e das tecnologias do conhecimento. Nela, o conceito sustentabilidade é quase inerente à sua finalidade, apenas sem, talvez, sua conformação em disciplina estanque e de destaque acadêmico.

A Pontifícia Universidade Católica do Rio de Janeiro foi instituída por deliberação do I Concílio Plenário Brasileiro como centro nacional de cultura católica, reconhecida pelo governo federal do Brasil nos termos do Decreto Lei n 8.631, de 15 de janeiro de 1946, e oficializada canonicamente por Decreto da Sagrada Congregação dos Seminários e Universidades em 20 de janeiro de 1947. Constitui-se em instituição privada de caráter confessional, comunitário e filantrópico, sem fins lucrativos, dedicada ao ensino, à pesquisa e à extensão (PUC-RIO, 2012). Declarada de utilidade pública federal pelo Decreto $n^{\circ}$ 43.454, de 26 de março de 1958, a PUC-Rio, para o cumprimento de sua missão de servir ao Brasil e à comunidade universal por meio da busca da verdade, destina todos os seus recursos: (i) à promoção da cultura, nos planos intelectual, estético, moral e espiritual; (ii) ao desenvolvimento do ensino, da pesquisa e da extensão em uma visão de mundo pluralista do conhecimento; e (iii) à promoção do intercâmbio e da cooperação com instituições públicas e privadas, nacionais e 
estrangeiras, especialmente as de caráter educacional, científico e cultural, na intenção de emprestar universalidade ao sentido de sua missão.

Compassivo e cônscio de sua responsabilidade sobre as questões sensíveis da sustentabilidade, o atual reitor da PUC-Rio, Pe. Josafá Carlos de Siqueira S. J., fundou em 1999 o Núcleo Interdisciplinar de Meio Ambiente (Nima) com o objetivo de aglutinar em um lócus comum as competências multidisciplinares internas e estabelecer a desejável interação entre a universidade e a sociedade para o fomento de projetos socioambientais. Há 13 anos, o Nima vem realizando projetos em parceria com escolas, empresas, municípios e instituições nacionais e internacionais, conciliando a escala local à global. Na visão do reitor da universidade (SIQUEIRA, 2009), deve pautar o seu compromisso maior na ética ambiental voltada para a transformação da cultura antropocêntrica com vistas à integralização do ser humano pela preservação da biodiversidade e do meio ambiente, integrando o pensamento técnico-científico ao axiológico.

Submissa a tais objetivos e compromissos, a PUC-Rio mantém processo permanente de autoavaliação de desempenho em busca do aperfeiçoamento institucional continuado. Em resposta às recomendações do Colóquio Global de Reitores de Universidades, realizado em dezembro de 2007 por solicitação do secretário geral das Nações Unidas, a PUC-Rio abraçou o desafio de tornar-se uma universidade orientada para a promoção da sustentabilidade e para o desenvolvimento sustentável. Uma decisão com o propósito de transformar o campus em um grande laboratório que estimule o aluno e o professor a alterarem seus hábitos. A universidade, portanto, incorporou em sua missão a busca de soluções de garantia da sustentabilidade e de inovações que balizem a transição para uma economia verde $e$, consequentemente, venham mitigar os efeitos perversos das mudanças climáticas. Esse desafio, que exige esforços acadêmicos extraordinários, vem sendo enfrentado com determinação e constância (PUC-RIO/NIMA, 2009).

De forma a planejar, materializar e operacionalizar a sustentabilidade, a PUC-Rio criou, em 2009, uma agenda ambiental sob 
a coordenação e responsabilidade do Nima. Essa agenda ambiental, congregando naturalmente uma pluralidade de pensamentos e conhecimentos acerca do conceito sustentabilidade devido à multidisciplinaridade da sua composição, compreende um conjunto de práticas que permitem e estimulam a sustentabilidade e a qualidade de vida socioambiental no campus universitário. Estrutura-se em sete eixos temáticos: biodiversidade; água; energia; atmosfera; materiais; resíduos; e educação ambiental. Cada um dos eixos esclarece, na sua introdução, o posicionamento ético-ambiental assumido; um planejamento de execução; e um conjunto de objetivos de curto, médio e longo prazos (PUC-RIO/NIMA, 2012). Em seu quarto ano, desde sua implantação, já são percebidos resultados positivos. No GreenMetric World University Ranking 2011 - instrumento de classificação do comprometimento das universidades do mundo inteiro com a sustentabilidade-, a PUC-Rio ocupou a $66^{a}$ posição no ranking mundial entre 178 instituições avaliadas e a $1^{\text {a }}$ posição no ranking nacional (GREENMETRIC, 2012). Atualmente, a Agenda Ambiental PUC-Rio conta com a participação do grupo de pesquisa Universidade Sustentável, composto de professores de diversas unidades da instituição que acompanham o processo de implantação da agenda e orientam alunos de graduação e de pós-graduação na produção de monografias, dissertações e teses destinadas ao equacionamento de soluções concretas aos desafios impostos pela busca da sustentabilidade.

\section{Ações da pós-graduação em metrologia, qualidade, inovação e sustentabilidade}

O Programa de Pós-Graduação em Metrologia para Qualidade e Inovação (PósMQI/PUC-Rio), por meio de seu recém implantado pilar da sustentabilidade, tem sua origem em um esforço acadêmico conjunto dos departamentos do Centro Técnico Científico da Universidade. Beneficiando-se da intrínseca multidisciplinaridade de uma universidade global como a PUC-Rio, o PósMQI visa formar um profissional interdisciplinar, com características próprias, distintas das áreas que caracterizam a sua formação original. 
Aberto a profissionais de diversas formações profissionais, - PósMQI/PUC-Rio não objetiva especializar engenheiros, administradores, biólogos, físicos, químicos, mas capacitá-los de forma integral para atuar na interface da ciência das medições e dos saberes. A interdisciplinaridade refere-se tanto à convergência de duas ou mais áreas do conhecimento quanto à identificação e pesquisa de novos modos de relacionamento entre elas. O PósMQI atua em áreas do conhecimento que possam contribuir para o avanço da ciência, da arte e da tecnologia das medições e da instrumentação. Contribui para a difusão da qualidade em novos campos da atividade humana e para a criação e agregação de valor mediante dinâmicas de inovação tecnológica. Esse é um processo que se torna cada vez mais crítico na sociedade do conhecimento que se estrutura nesse início de século e que requer aceleração na transferência de conhecimentos de uma área para outra.

Com a consolidação da sua visão institucional, o PósMQ। transcendeu o uso restringente da metrologia como instrumento de competitividade industrial e de melhoria de produtos e processos em disputa no mercado. Evoluiu para uma visão que expande a instrumentalização das medições rumo à equidade social, prosperidade econômica, valoração e preservação ambiental. No contexto de sua visão ampla da ciência, da qualidade (adequação ao uso), da competitividade, da tecnologia e da arte das medições, o PósMQI passou a promover o ensino e a pesquisa em metrologia segundo um modelo sistêmico voltado à sustentabilidade, modelo que alinha-se aos capítulos da Agenda 21 (1995), integrando as dimensões social, econômica, cultural e ambiental do desenvolvimento sustentável à sociedade industrial e a demais organizações. No contexto dessa nova lógica da qualidade e inovação orientadas para a sustentabilidade, o PósMQI formalizou junto à Capes a mudança de sua área de concentração, evoluindo de "metrologia para qualidade industrial" para "metrologia para qualidade e inovação", enaltecendo a sustentabilidade em sua identidade institucional.

Ao assegurar uma formação sólida e interdisciplinar, o PósMQI/PUC-Rio capacita profissionais a fazer uso da ciência das 
medições e da instrumentação no dia a dia de suas atividades. Em particular, prepara profissionais para superar os desafios do mercado de trabalho em um mundo globalizado e, em grande medida, está atento à necessidade de internalização da noção de sustentabilidade e do desenvolvimento sustentável. Estimula, assim, a busca de soluções para problemas próprios de setores dinâmicos da economia e de segmentos relacionados à manutenção e melhoria da qualidade de vida, da biodiversidade e do acesso à cidadania. Em síntese, no cumprimento de sua missão institucional, o PósMQl objetiva: (i) formare qualificar profissionais interdisciplinares, inovadores, empreendedores e sensiveis às questões de competitividade e sustentabilidade; (ii) formar e qualificar profissionais para o ensino e a pesquisa, com o foco na qualidade, inovação e sustentabilidade; e (iii) desenvolver atividades de P\&D em setores promissores na geração de inovações tecnológicas e desenvolvimento sustentável.

Três são as linhas de pesquisa do Programa: instrumentação e medição (confiabilidade metrológica e inovação de técnicas e métodos de medição); gestão estratégica, inovação e sustentabilidade (modelos de gestão estratégica da inovação; fundamentos históricos, antropológicos e científicos do desenvolvimento sustentável; e mudanças climáticas); e redes inteligentes - smart grid -, voltadas às inovações tecnológicas da comunicação e informação associadas às redes inteligentes de energia.

Sustentabilidade é tema recorrente em todas essas linhas de pesquisa. Introduz uma nova realidade, criando novas perspectivas para evoluir e encontrar soluções práticas no contexto de um ambiente regido por inovações tecnológicas. Eficiência energética; eficiência estratégica e operacional; métricas de ecoeficiência; tecnologias de processamento de smart grid; fontes alternativas de energia; pegada ecológica; pegada de carbono; estratégia corporativa de carbono; mecanismos de desenvolvimento limpo; estratégias de adaptação e mitigação às mudanças climáticas; tarifas mais ajustadas e justas; e participação colaborativa dos consumidores são apenas algumas das questões-chave trabalhadas nessas linhas de pesquisa. As dimensões continentais do Brasil impõem desafios para superar a defasagem de 
infraestrutura ainda existente. Estabelece-se, assim, a interconexão dos sistemas e subsistemas, integrando o País e assegurando o acesso à energia e transmissão de informação, às condições básicas de vida e à cidadania para o desenvolvimento sustentável.

A grade curricular do PósMQl foi estruturada segundo as linhas de pesquisa do programa. A grade incorpora um conjunto de disciplinas optativas e eletivas que complementam as disciplinas obrigatórias, totalizando os 24 créditos acadêmicos requeridos pelo mestrado acadêmico stricto sensu. O PósMQI reestruturou sua missão e identidade, atualizando sua grade curricular e suas linhas de pesquisa com base no monitoramento permanente das demandas por capacitação profissional e pesquisas e nos desafios impostos pela missão PUC-Rio para tornar-se um modelo de universidade sustentável. A sustentabilidade foi introduzida na nova grade curricular por meio de disciplinas específicas. Entre elas, Metrologia para o Desenvolvimento Sustentável; Metrologia e Estratégia Corporativa de Carbono; Elaboração de Projetos e Relatórios em Sustentabilidade; Sistemas de Mensuração de Sustentabilidade; Gestão Estratégica da Inovação; Aprendizagem Organizacional e Cultura Metrológica; Normalização e Sistemas de Gestão; Regulação, Avaliação e Gestão de Riscos; Biometrologia, Medição Bioeletromagnética, Introdução às Redes Inteligentes de Energia; Infraestrutura de Redes Inteligentes de Energia; Regulação no Setor Energético; Eficiência Energética; e Cidades Inteligentes.

A estrutura da rede de pesquisa, conhecida pela articulação institucional e pelos sistemas de colaboração e cooperação entre pesquisadores e instituições, otimiza e proporciona a concreta realização do conhecimento interdisciplinar. Proporciona um marco analítico para a identificação e caracterização de novos e inovadores objetos de pesquisa. Torna-se crítica para a geração e agregação de valor, para a consolidação de vantagens competitivas, para a difusão da cidadania e para o entendimento da sustentabilidade. Ano após ano, o PósMQI se fortalece pelo esforço bem sucedido no investimento da articulação institucional interna, que congrega atores da própria universidade, e externa, por meio da colaboração e cooperação com centros de pesquisa 
e empresas do Brasil e do exterior. No âmbito externo, beneficia-se da sua capacidade de articulação para viabilizar o enriquecimento de sua produção intelectual, participação e representação em fóruns específicos, na execução de projetos e no registro de patentes. Ao longo dos últimos anos, o programa tem participado de projetos de P\&D desenvolvidos por organizações internacionais, entre os quais se incluem projetos de avaliação da infraestrutura nacional da qualidade (metrologia, normas, avaliação da conformidade) de países europeus e asiáticos e projetos de orientação a governos da América Latina na estruturação de seus sistemas regulatórios e de metrologia. Cada vez mais, o programa é procurado por candidatos ao mestrado de outros países (e.g.: o programa já graduou profissionais de Peru, Paraguai, Bolívia, Colômbia, Panamá, Costa Rica e Alemanha).

Como parte de sua estratégia, em 2010, o PósMQI constituiu um grupo de pesquisa (ECOMQI: Metrologia para o Desenvolvimento Sustentável) para atuar ativamente na interface da metrologia com as áreas da sustentabilidade. O grupo foi cadastrado no diretório de grupos de pesquisa do CNPq. O ECOMQI considera que o paradigma do desenvolvimento sustentável pressupõe a institucionalização da inovação e da sustentabilidade nos processos e nas condições políticas, culturais, sociais, técnicas, econômicas e ambientais. Considera a responsabilidade social em seu sentido lato, percebendo as estratégias de adaptação e mitigação às mudanças climáticas como estratégias inteligentes para consolidar a sustentabilidade e assegurar a melhoria da qualidade de vida. O ECOMQI prevê a articulação de políticas e projetos de interesse para o desenvolvimento do tema e a mobilização de competências existentes nos centros de pesquisa, universidades, empresas conscientes, órgãos públicos e de fomento, com vistas a criar sinergias mobilizadoras. Assim atuando, potencializa os esforços no sentido de articular o diálogo e organizar e estimular a promoção do desenvolvimento científico e tecnológico em bases sustentáveis.

No ano de 2011, o PósMQI inseriu-se oficialmente na agenda ambiental da Universidade, propondo um conjunto consistente de indicadores de sustentabilidade para a avaliação dos resultados da implantação da agenda, definidos pela análise dos conteúdos- 
chave expressos nas diretrizes de cada eixo temático (COSTA, 2012). Merecedor do segundo lugar do Prêmio da XV Mostra PUC: Iniciativas Sustentáveis - Sustentabilidade: um compromisso de todos. Categoria: Pós-Graduações, Dissertações e Teses.

No ano de 2012, um segundo trabalho avaliou o potencial do Departamento de Química da Universidade para adotar métodos de Química Analítica Verde, estabelecendo conformidade aos princípios de Química Verde internacionalmente aplicáveis (OLIVEIRA, 2012).

Em 2013, um terceiro trabalho propôs um conjunto de métricas para a valoração dos recursos e serviços ecossistêmicos da palmeira Euterpe edulis Martius (Juçara) na Floresta Atlântica Tropical (FERREIRA, 2013). Trabalho alinhado com as demandas estabelecidas pela Agenda Ambiental da PUC-Rio e pelo Programa Frente Pró-Juçara do estado do Rio de Janeiro (NIMA, 2013), a ser lançado em evento oficial no dia 3 de junho de 2013 na PUC-Rio com o plantio de mil mudas de Juçara no campus da universidade. Entre suas principais ações, cabe salientar que o programa Frente Pró-Juçara estabelece o plantio e o monitoramento de 10 milhões de mudas de Juçara em áreas degradadas de Floresta Atlântica no estado do Rio de Janeiro até 2016.

Atualmente, em colaboração com o Centre for Climate Change Impacts Adaptation \& Modeling (CCIAM) da Faculdade de Ciências da Universidade de Lisboa (FC-UL), o PósMQI ingressou no projeto de colaboração internacional da União Europeia Bottom-up Climate Adaptation Strategies towards a Sustainable Europe(BASE, 2013). Além disso, dois novos trabalhos de mestrado estão sendo desenvolvidos: um dedicado à formulação de métricas e indicadores de ecoeficiência em Estratégia Corporativa de Carbono; e o outro, à formulação de métricas para a análise da pegada de carbono de instituições de ensino superior, tendo como estudo de caso a PUC-Rio.

O PósMQl já possui forte inserção em atividades de P\&D voltadas diretamente à inovação e sustentabilidade nos setores de energia elétrica, petróleo e gás. Entre os projetos, destacam-se: (i) 
Projeto de P\&D Indústrias do Futuro e Tecnologias Emergentes, em parceria com o Centro de Gestão e Estudos Estratégicos, realizado no período de março de 2010 a setembro de 2011; (ii) Projeto de P\&D Produção Limpa: Química Sustentável, Tendências, Novos Negócios e Reciclagem, em parceria com o Centro de Gestão e Estudos Estratégicos (CGEE/MCT), realizado no período de julho de 2009 a fevereiro de 2011; (iii) Projeto de P\&D Light-Aneel P\&D 80/11, em andamento, intitulado Desenvolvimento Tecnológico e Inovação na Utilização de Tecnologia Fotovoltaica e sua Integração Inteligente com a Rede de Distribuição: uma Ação Voltada a Grandes Clientes da Light. Em parceria com a concessionária, o P\&D desenvolve um sistema inteligente acoplado a um sistema supervisório para a conversão fotovoltaica, incluindo monitoramento, controle e gerenciamento da energia solar. Assistido por sensores e equipamentos de aquisição de dados operando em tempo real e contínuo, um sistema fotovoltaico para a geração distribuída será instalado no Museu da Energia da Light, atendendo a demandas específicas de iluminação, integração com a rede e sensibilização do público do Museu para o uso de energias alternativas renováveis. Original na sua concepção, o P\&D incorpora a avaliação complementar da estratégia corporativa de carbono na utilização da energia fotovoltaica.

No âmbito de sua linha de pesquisa Gestão Estratégica, Inovação e Sustentabilidade, atualmente o PósMQI colabora com o Centre for Climate Change Impacts Adaptation \& Modeling (CCIAM) da Faculdade de Ciências da Universidade de Lisboa (FC-UL); com o Programa de Doutorado em Alterações Climáticas e Politicas de Desenvolvimento Sustentável da Universidade de Lisboa, Universidade Técnica de Lisboa e Universidade Nova de Lisboa; com o grupo de pesquisa interinstitucional Rede de Tecnologia da Juçara, que congrega pesquisadores de diversas instituições nacionais; e com os empreendimentos Light - Concessionária de Energia; Petrobrás - Energia; Amável - a Mata Atlântica Sustentável -; e CBPAK Embalagens Compostáveis. 


\section{Considerações finais}

A metrologia - considerada por especialistas como uma espécie de "tecnologia invisível", cujos resultados nem sempre são facilmente perceptíveis - não necessariamente é compreendida pelos cidadãos comuns ou pelos governos, que, por falta de sensibilidade técnica, não percebem o resultado da sua ação no meio ambiente e o impacto econômico que resulta do uso adequado de sistemas de medição na redução de desperdícios e retrabalho e, principalmente, no seu papel estratégico na construção das modernas sociedades industriais. Ao longo dos anos, a importância da infraestrutura nacional de qualidade (i.e.: acesso a serviços confiáveis de metrologia, normalização e avaliação da conformidade) - um bem público do ponto de vista da teoria econômica - tem sido subestimada no desenvolvimento de políticas econômicas, em que o comércio é um componente essencial. Mas foi apenas uma década atrás que o International Committee of Weights and Measures (CIPM), apoiado pelos diretores dos institutos nacionais de metrologia (NMI) de 38 estados-membros da Convenção do Metro e por representantes de organizações internacionais de metrologia, acreditação e certificação (BIPM, OIML, Ilac e IAF), introduziu um regime global para estabelecer a equivalência global dos sistemas nacionais de metrologia. Criou-se, assim, a base para o Acordo de Reconhecimento Mútuo (CIPM-MRA), que estabelece o consenso para que medições possam ser intercomparadas. Esse é um passo fundamental para estabelecer consenso mundial de resultados de medições críticas e impactantes (e.g.: qualidade do ar, água, bem estar, pegadas de carbono) que fundamentam os tratados internacionais de manutenção dos recursos e serviços ecossistêmicos.

A busca da elaboração de um modelo de desenvolvimento em bases sustentáveis revela um conjunto de problemas estruturais e traz para as sociedades um desmedido desafio. Tal modelo de desenvolvimento deverá ser capaz de beneficiar esse fenômeno único que é a vida e contribuir para um projeto civilizatório lastreado em parâmetros de prosperidade, dignidade e bem estar, de tal sorte que permaneça para sempre assegurado o capital da vida, esse bem principal da Terra. A conquista da sustentabilidade irá exigir 
uma reforma da mentalidade cultural atual em que o desperdício, a depredação ambiental e o desrespeito às fontes finitas de preservação da natureza foram e estão violentadas avassaladoramente pela força gananciosa do homem, primitivo e incivilizado ainda. Deverá contar para isso com forças revolucionárias naturais da sociedade para que o salto qualitativo para a habitabilidade futura possa ser dado sem impactos negativos no estágio atual da vida social.

As universidades e os programas de pós-graduação cumprem um papel decisivo nessa reavaliação, já que a sustentabilidade não resulta da geração espontânea mecânica, mas da interferência do homem na transformação dos valores que se querem subsistindo à linha da existência. É preciso garantir a confiabilidade e a justa medida dos saberes e indicadores que regem as tomadas de decisão. É preciso compreender os comportamentos, as singularidades, os limites e as condições que regem os processos ecossistêmicos. É preciso qualificar e orientar a inovação para a manutenção das condições de habitabilidade do planeta. Uma vez compreendido o modo como a sustentabilidade se projeta na Terra, na vida e na sociedade, poder-seão formular hipóteses confiáveis para um modelo de desenvolvimento de base sustentável.

Partindo-se do pressuposto de que futuras tecnologias e inovações tecnológicas impulsionarão negócios e relacionamentos mais sustentáveis, propiciando às instituições novas opções de criação e agregação de valor, o desafio é descobrir de que maneira é possível atuar em ambientes cada vez mais complexos. E mais, de ser capaz de incorporar a visão da sustentabilidade social, econômica, ambiental e cultural em suas estratégias, seus processos e suas atividades. Nesse contexto, o PósMQI/PUC-Rio introduz um novo olhar à sua missão institucional e às pesquisas em metrologia, qualidade e inovação. Contribui para tal a interdisciplinaridade que é intrínseca à metrologia, não denotando uma simples justaposição de outras áreas do conhecimento ou aglutinação de esforços estanques desvinculados, mas uma busca de produção de novas e inovadoras soluções para a geração e agregação de novo valor - a sustentabilidade. 
Fundamentado em sua experiência nos últimos 16 anos e atento às novas demandas advindas de uma sociedade da inovação e da informação, o PósMQI/PUC-Rio continuará evoluindo. Suas ações se encaminharão no sentido de preencher um vazio existente na formação de profissionais com vocação interdisciplinar em metrologia e com sólidos conhecimentos complementares, que vão da tecnologia industrial básica à sustentabilidade. Isso sem perder de vista o desafio constante da extensão e o aprofundamento da qualidade, voltados para os interesses do meio acadêmico, do setor industrial e de serviços da sociedade brasileira em geral.

A atenção às inovações e aos novos conhecimentos gerados deve continuar balizando o processo de evolução do Programa de PósGraduação em Metrologia da PUC-Rio à luz do conceito de progresso científico de Dewey (1952, p. 271), para quem "todo gran avance de la ciencia se ha devido a una nueva audacia de la imaginación”. Trazendo para a cena de discussão a inconveniência de se considerar de forma estanque ciência e filosofia, Dewey argumenta que à filosofia cumpre refletir e apropriar-se dos resultados específicos dos conhecimentos gerados, transformando-os em ações práticas que favoreçam o homem. Em sentido convergente, propõe também o reordenamento dos conceitos de arte (estética) e ciência, esmaecendo por completo o entendimento diverso da natureza de cada uma delas: experimentação, inerente à ciência; e impressão, inerente à arte. Isso pelo fato de que em ambos os objetos da expressão/experimentação, os elementos constitutivos naturais e funcionais, permanecem os mesmos, em ambos variando a consequência que depende de valor na sua função de desvelar ou expressar a natureza íntima da natureza.

Não resta dúvida de que a criação de um mundo sustentável necessitará, antes de qualquer medida, da imaginação que crie métodos de convencimento antes de aplicar os conhecimentos e toda a ciência disponíveis para chamar a técnica a serviço de sua implementação.

A PUC-Rio está comprometida com a sustentabilidade. Participa ativamente, em escala global, do debate sobre a sustentabilidade. Definindo o tom, o reitor da universidade é autor de aproximadamente 
60 artigos científicos e 12 livros voltados para as temáticas da educação ambiental, ética socioambiental e espiritualidade ecológica. O seu recente livro Rio+20: Reflexões sobre a sustentabilidade ambiental (SIQUEIRA, 2012) discute a inquietação da sociedade global e regional sobre essa temática, que envolve aspectos econômicos, climáticos e éticos. Na visão do filósofo Danilo Marcondes, que apresenta o livro, o reitor da PUC-Rio

\begin{abstract}
mostra a necessidade de superar a dicotomia entre o ser humano e a natureza, em uma visão integrada da realidade natural em que habitamos. É essa postura da ética do cuidar e da responsabilidade pelo que não é nosso, mas que consiste no meio ambiente que compartilhamos com todos os seres vivos e do qual somos parte integrante, que forma o pano de fundo dessas reflexões. Isso aponta para a adoção de uma racionalidade dialógica e integradora para além da racionalidade instrumental ainda dominante em uma visão da técnica como dominação e submissão da natureza (SIQUEIRA, 2012, prefaciais).
\end{abstract}

\title{
Agradecimentos
}

À Capes, pela bolsa de pós-doutoramento (PNPD 2007) concedida a um dos autores, assim contribuindo para a consolidação do pilar da sustentabilidade no Programa de Pós-Graduação em Metrologia para Qualidade, Inovação e Sustentabilidade da PUC-Rio. Ao professor Dr. Luiz Felipe Guanaes Rego, diretor do Núcleo Interdisciplinar de Meio Ambiente (Nima), pela oportunidade de participação do PósMQI na Agenda Ambiental da Universidade e pela criteriosa leitura crítica do texto.

Recebido 21/09/2012

Aprovado 25/07/2013 


\section{Referências bibliográficas}

AGENDA 21. Conferência das Nações Unidas sobre Meio Ambiente e Desenvolvimento. Brasília: Câmara dos Deputados, 1995.

BASE. Bottom-up Climate Adaptation Strategies towards a Sustainable Europe. Disponivel em: < http://base-adaptation.eu>. Acesso em: 31 maio 2013.

BOFF, L. Sustentabilidade. O que é? O que não é? Rio de Janeiro: Editora Vozes, 2012.

BRUNTDLAND, G. H. Our common future. The World Commission on Environment and Development. New York: Oxford University Press, 1987.

CARLOWITZ, H. C. Sylvicultura Oeconomica. Anweisung zur wilden Baum-Zucht. Freiberg: Reprint der tu bergakademie, 2000.

COSTA, A. V. O. Indicadores de Sustentabilidade para Instituições de Ensino Superior: Uma Contribuição para a Agenda Ambiental PUCRio. 2012. Dissertação (Mestrado em Metrologia)- Programa de PósGraduação em Metrologia, Pontifícia Universidade Católica do Rio de Janeiro, Rio de Janeiro, 2012.

COPERNICUS GUIDELINES. The university chapter for sustainable development. 1993. Disponivel em: <http://www.iisd.org/educate/ declarat/coper.htm>. Acesso em: 29 ago. 2012.

DEWEY, J. La busca de la certeza: un estudio de la relación entre el conocimiento y la acción. Tradução Eugenio Ímaz. México/Buenos Aires: Fondo de Cultura Económica, 1952.

ELKINGTON, J. Cannibals with forks: The triple botton line of 21st Century Business. Journal of business ethics, v. 23, n. 2, p. 229-231, 1990. 
FERREIRA, L. Avaliação de sustentabilidade e captura de carbono na Floresta Atlântica Tropical: formulação de métricas e estudo de caso da Euterpe edulis Martius. 2013. Dissertação (Mestrado em Metrologia)Programa de Pós-Graduação em Metrologia, Pontifícia Universidade Católica do Rio de Janeiro, Rio de Janeiro, 2013.

GREENMETRIC UI World Universities Ranking. Guidelines of UI GreenMetric World Universities Ranking 2011. 2012. Disponivel em: <http://greenmetric.ui.ac.id>. Acesso em: 27 ago. 2011.

GROBER, U. Modewort mit tiefen Wurzeln: Kleine Begriffsgeschichte von 'sustainability' und 'Nachhaltigkeit'. In: ALTNER, G.; LEITSCHUHFECHT, H.; SIMONIS, U. E. Jahrbuch Ökologie 2003. München: Beck, 2002. p. 167-175.

IPCC. Climate Change: Synthesis Report. Fourth assessment report. An Assessment of the intergovernmental panel on the climate change. Published by the Intergovernmental Panel on Climate Change. Geneva: 2007. p. 44-5.

LELLO Universal. Dicionário Enciclopédico Luso-Brasileiro. v. 2. Portugal: Editora Lello e Irmãos Editores Porto, 1926. p. 1130.

LUKMAN, R. G.; GLAVIC, P. What are the key elements of a sustainable university? Clean Technologies and Environmental Policy, v. 9, p.103$114,2007$.

LUNEBURG DECLARATION on higher education for sustainable development. 2001. Disponivel em: <http://portal.unesco.org/ education/en/files/37585/11038209883LuneburgDeclaration. pdf/ LuneburgDeclaration.pdf>. Acesso em: 29 ago. 2012.

MEADOWS, D.; RANDERS, J.; MEADOWS, D. Limits to Growth: The 30Year Update. Vermont: Chelsea Green Publishing Company, 2004.

NIMA - NÚCLEO INTERDISCIPLINAR DE MEIO AMBIENTE. Um fruto brasileiro. Disponivel em: <http://www.nima.puc-rio.br/index. php/pt/todas-as-notas/4115-lancamento-do-projeto-frente-projucara>. Acesso em: 30 maio 2013. 
OLIVEIRA, B. Química Analítica Verde: proposições para a Agenda Ambiental PUC-Rio. 2012. Dissertação (Mestrado em Metrologia)Programa de Pós-Graduação em Metrologia, Pontifícia Universidade Católica do Rio de Janeiro, Rio de Janeiro, 2012.

PUC-RIO - PONTIFÍCIA UNIVERSIDADE CATÓLICA DO RIO DE JANEIRO. Marco Referencial, Estatuto, Regimento, Constituição Apostólica, Ex Corde Ecclesiae. Rio de Janeiro: Editora LibraryThing, 2001.

PUC-RIO/NIMA - PONTIFÍCIA UNIVERSIDADE CATÓLICA DO RIO DE JANEIRO/NÚCLEO INTERDISCIPLINAR DE MEIO AMBIENTE. Agenda ambiental-PUC-Rio. Rio de Janeiro: PUC/Núcleo Interdisciplinar de Meio Ambiente, 2009. Disponivel em: <http://www.nima.puc- rio.br>. Acesso em: 21 jan. 2012.

Sobre o NIMA. 2012. Disponivel em: <http://www.nima.pucrio.br>. Acesso em: 21 jan. 2012.

SIQUEIRA, J. C. Ética sócio ambiental. Rio de Janeiro: Editora PUC-Rio, 2009.

Rio +20 - Reflexões sobre a sustentabilidade socioambiental. Rio de Janeiro: Editora PUC-Rio, 2012.

SOHN, L. B. The Stockholm Declaration on the human environment. Harvard International Law Journal, v. 14, n. 3, p. 423-515, 1973.

THE TBILISI DECLARATION. Intergovernmental Conference on Environmental Education. Final Report. USSR: 1977. Disponivel em: <http://unesdoc.unesco.org/images/0003/000327/032763eo.pdf>. Acesso em: 29 ago. 2012.

THE TALLOIRES DECLARATION. Association of University Leaders for a Sustainable Future. 1990. Disponivel em: <http://www.ulsf.org/ talloires_declaration.html>. Acesso em: 29 ago. 2012. 
THE HALIFAX DECLARATION. Creating a Common Future: University Action for Sustainable Development. 1991. Disponivel em: <www.iauaiu.net/content/rtf/sd_dhalifax.rtf>. Acesso em: 29 ago. 2012.

THE KYOTO DECLARATION. Ninth International Association of Universities Round. 1993. Disponivel em: <http://www.iisd.org/educate/ declarat/kyoto.htm>. Acesso em: 29 ago. 2012.

THE THESSALONIKI DECLARATION. International Conference Environment and Society: Education and Public Awareness for Sustainability. 1997. Disponivel em: <http://resources.spaces3.com/f49d326a-5930-45cfa9ef-4d23a0670a6d.pdf>. Acesso em: 29 ago. 2012.

THE SWANSEA DECLARATION. Association of Commonwealth Universities' Fifteenth Quinquennial Conference. 1993. Disponivel em: <http://www.iisd.org/educate/declarat/swansea.htm>. Acesso em: 29 ago. 2012.

THE UBUNTU DECLARATION. Ubuntu Declaration on Education, Science and Technology for Sustainable Development. 2002. Disponível em: <http:/ / www.ias.unu.edu/sub_page.aspx?cat|D=108\&dd|ID=304>. Acesso em: 29 ago. 2012.

UNCSD/RIO+20. The future we want. 2012. Disponivel em: <http:// www.rio20.gov.br>. Acesso em: 30 ago. 2012.

WORLD declaration on higher education for the twenty-first century: vision and action. 1993. Disponivel em: <http://www.unesco.org/ education/educprog/wche/declaration_eng.htm>. Acesso em: 29 ago. 2012. 